\title{
8
}
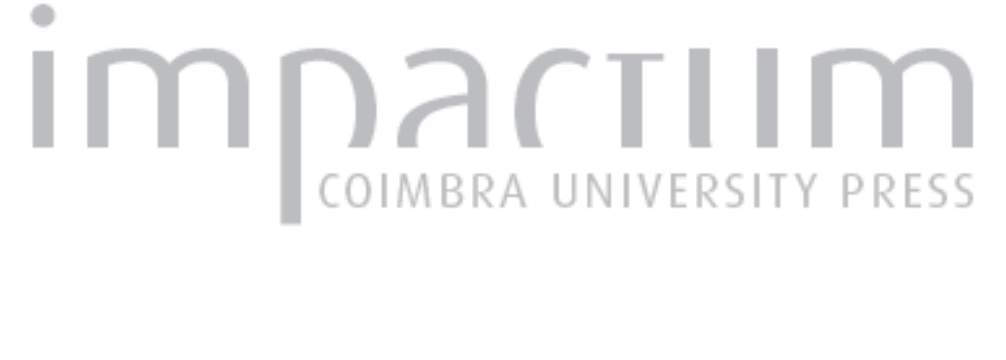

\section{Hannah Arendt e o problema da vontade em Santo Agostinho}

\section{Autor(es): Hornich, Daner}
Publicado por: Universidade Católica de Petrópolis; Instituto Brasileiro de Informação em Ciência e Tecnologia

URL

persistente:

URl:http://hdl.handle.net/10316.2/33076

DOI:

DOI:http://dx.doi.org/10.14195/1984-6754_1-2_2

Accessed : $\quad$ 26-Apr-2023 01:34:26

A navegação consulta e descarregamento dos títulos inseridos nas Bibliotecas Digitais UC Digitalis, UC Pombalina e UC Impactum, pressupõem a aceitação plena e sem reservas dos Termos e Condições de Uso destas Bibliotecas Digitais, disponíveis em https://digitalis.uc.pt/pt-pt/termos.

Conforme exposto nos referidos Termos e Condições de Uso, o descarregamento de títulos de acesso restrito requer uma licença válida de autorização devendo o utilizador aceder ao(s) documento(s) a partir de um endereço de IP da instituição detentora da supramencionada licença.

Ao utilizador é apenas permitido o descarregamento para uso pessoal, pelo que o emprego do(s) título(s) descarregado(s) para outro fim, designadamente comercial, carece de autorização do respetivo autor ou editor da obra.

Na medida em que todas as obras da UC Digitalis se encontram protegidas pelo Código do Direito de Autor e Direitos Conexos e demais legislação aplicável, toda a cópia, parcial ou total, deste documento, nos casos em que é legalmente admitida, deverá conter ou fazer-se acompanhar por este aviso.

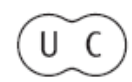



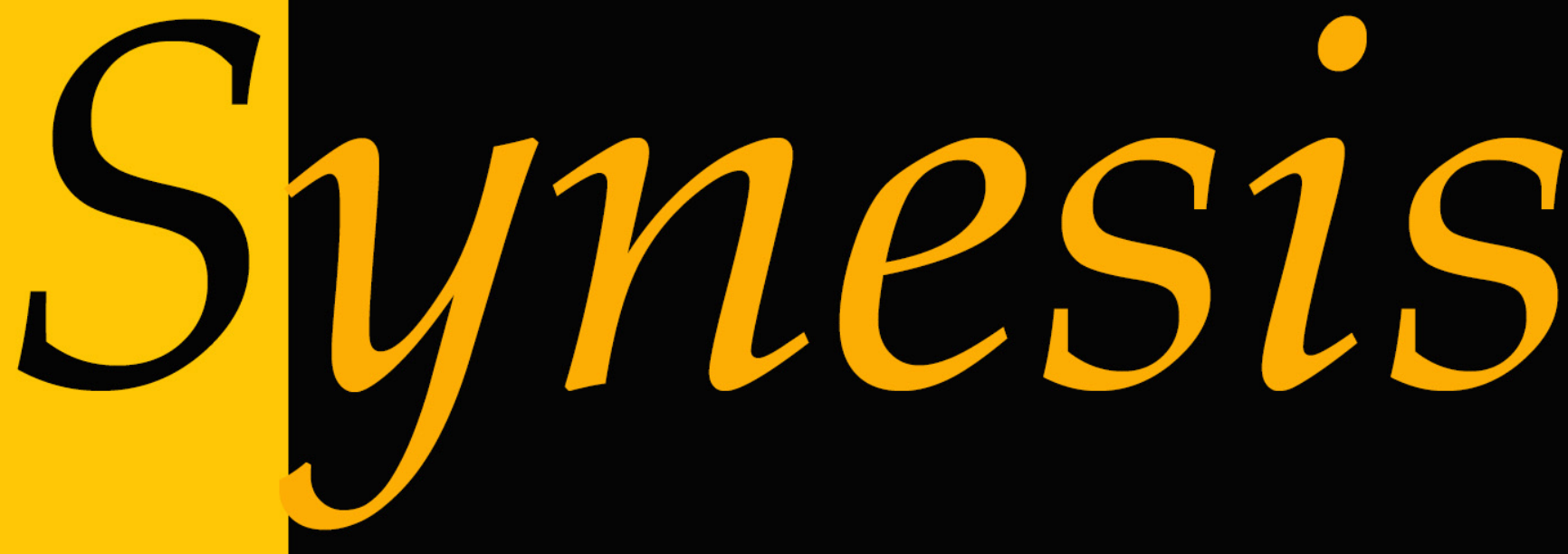

Revista do Centro de Teologia e Humanidades ISSN 1984-6754

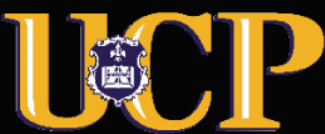




\title{
Hannah Arendt e o problema da vontade em Santo Agostinho
}

\author{
DANER HORNICH ${ }^{1}$
}

\section{Resumo}

$\mathrm{O}$ artigo traz uma reflexão sobre a faculdade da vontade e o problema da liberdade em Santo Agostinho, na perspectiva arendtiana. Para isso, ele se inicia com uma visão geral, ou panorâmica, de Santo Agostinho e de sua importância enquanto homem e pensador, seguida de uma análise mais específica da questão da vontade em Santo Agostinho.

Palavras chaves: faculdade da vontade $\cdot$ problema da liberdade $•$ Santo Agostinho - Hannah Arendt

\begin{abstract}
The article brings a reflection onto the faculty of will and the freedom trouble in Saint Augustine, in the arendtiana perspective. For then, he starts with a general vision, or panoramic, of Saint Augustine and his importance like man and thinker; followed by an analyses more specific of question of will in Saint Augustine Keywords: Faculty of will $\bullet$ freedom troubles $・$ Saint Augustine $\bullet$ Hannah Arendt

\footnotetext{
1 Doutorando em filosofia na Pontificia Universidade Católica de São Paulo. Mestre em Filosofia pela Pontificia Universidade Católica de São Paulo (2002). Graduado em Filosofia (1997). Atualmente é professor da Promoção do Ensino de Qualidade S/A e professor do Centro Universitário Salesiano de São
} Paulo.
\end{abstract}




\section{INTRODUÇ̃̃o}

Como Kant, o pensamento de Santo Agostinho é uma reflexão constante nas obras da Hannah Arendt, uma espécie de guia que norteia suas reflexões diante das experiências humanas que aparecem no mundo. Exemplo disso são sua tese de doutorado sobre Santo Agostinho (O conceito de amor em Santo Agostinho), suas citações chaves em Origens do totalitarismo e $A$ condição humana, nos ensaios Entre o passado e o futuro, A dignidade da política, Responsabilidade e julgamento e o livro A vida do Espírito, cuja leitura provocou este artigo.

$\mathrm{Na}$ trilha de Hannah Arendt, vou analisar o problema da vontade em Santo Agostinho, que é o problema da liberdade.

O artigo segue três linhas mestras: inicia com uma análise geral, ou panorâmica, de Santo Agostinho e sua importância enquanto homem e pensador; continua com uma visualização mais específica da questão da vontade em Santo Agostinho; e conclui com uma análise ou reflexão sobre a faculdade da vontade e o problema da liberdade em Santo Agostinho, na perspectiva arendtiana.

\section{Santo Agostinho, o primeiro fiLósofo Cristão e romano}

Hannah Arendt começa pontuando Santo Agostinho como o primeiro pensador cristão que soube juntar dois "mundos diferentes" - o grego-romano (filosófico) e o judaico-cristão (religioso) ${ }^{2}$ - por meio de suas reflexões filosóficas a partir das questões religiosas que emergiam de suas experiências vividas:

2 Essa perspectiva ou leitura da síntese da tradição ocidental grego-romano e judaico-cristã pode ser encontrada em GILSON. Étienne. Deus e a filosofia,2002, p. 41-43, LIMA VAZ Henrique C. de. Antropologia filosófica, 2004, p. 49-50; 56-59. BORNHEIM. Gerd. O sujeito e a norma. In: Novaies, Adauto (Org). Ética, 1992, p. 248-249.

http://www.ucp.br/htmlljoomlaBR/synesis/synesis.htm 
"Santo Agostinho - o primeiro filósofo cristão (...) o único filósofo que os romanos jamais tiveram -, foi o primeiro pensador que se voltou para a religião em função de perplexidades filosóficas"”.

O pensador que se inclinou para pensar a religião em função das perplexidades filosóficas é o mesmo que defendeu, em suas análises filosóficas, os dogmas nascentes da Igreja cristã com profundidade, articulação e originalidade filosófica. Exemplo dessa perspectiva é sua análise sobre o tratado Sobre a Trindade como uma orientação para a vida.

"Esta atitude pragmática, exigir da filosofia que seja a "guia da vida" (Cícero), é tipicamente romana; teve uma influência mais duradoura na formação do pensamento de Santo Agostinho do que de Plotino e os neoplatônicos, a quem ele devia tudo o que sabia sobre a filosofia grega"4.

Orientação para vida ou intuito de ser feliz, como uma atitude pragmática, é uma influência do pensamento romano na vida de Santo Agostinho que demarcava a possibilidade de filosofar com sentido e significado próprio para a vida: a busca da reflexão filosófica deve conduzir à felicidade. Sobre esse assunto, a felicidade, é salutar recordar as palavras de Sêneca, para entrar em sintonia com o mundo antigo em sua configuração greco-romano:

"Portanto, em primeiro lugar, devemos estabelecer antecipadamente o que buscamos atingir; depois, devemos examinar por onde podemos chegar lá mais rapidamente, e veremos pelo caminho, desde que seja o certo, quanto avançamos cada dia e quanto nos aproximamos do objeto para o qual nos impele um desejo natural"s.

3 ARENDT, Hannah. A vida do Espírito: o pensar, o querer e o julgar. Rio de Janeiro: Relumé Dumará, 1995, p. 248.

$4 \quad$ Idem Ibidem, p. 249.

5 SÊNECA. Sobre a vida feliz (De Vita Beata): edição bilíngue latim-português. São Paulo:

http://www.ucp.br/html/joomlaBR/synesis/synesis.htm 
Cícero imprime um caráter pragmático à busca da felicidade no caminho da sabedoria pela amizade, por meio da virtude do pensamento filosófico diante da efemeridade da existência humana:

"A sabedoria, que lhe atribuem, consiste em que você considere que tem dentro de si tudo o que é essencial para a sua existência e todos os azares da vida humana, como algo a ser dominado pela virtude" $"$

Depois dos exemplos desses dois pensadores da antiguidade romana, volto a Santo Agostinho para argumentar que o encontro com a felicidade, por meio da reflexão filosófica, é a possibilidade de encontrar a luz de Deus identificada nas noções metafísicas do ser no pensamento grego, como a ideia de imaterialidade, imutabilidade, inteligibilidade e de unidade ${ }^{7}$. Como argumenta Hannah Arendt em sua tese sobre o Conceito de amor em Santo Agostinho:

"A procura do bem é a procura de uma vida que não conhece a morte, a realidade plena da sua própria vida que está ao abrigo de toda perda. Esta vida sem morte é Deus, Deus amado e procurado enquanto eternidade, Esta eternidade é o futuro absoluto: se o homem deseja a realidade plena da sua própria vida, procura-se e deseja-se como porvir e não ama o eu na primeira pessoa, que encontra como dado na realidade terrestre"s.

Essas reflexões filosóficas da vida em busca da felicidade, do

Nova Alexandria, 2005, p. 19.

6 CÍCERO, Marco Túlio. Sobre a amizade (De Amicitia): Edição bilíngüe latim-português. São Paulo: Nova Alexandria, 2006, 19.

7 Cf. GILSON. Étienne. Deus e a filosofia, Lisboa: Edições, 70, 2002, p. 53.

8 ARENDT, Hannah. O conceito de Amor em São Agostinho. Lisboa: Instituto Piaget, 1997, $33-34$.

http://www.ucp.br/html/joomlaBR/synesis/synesis.htm 
summum bonum e do summum malum, conduziram Santo Agostinho a pensar a vida terrena e a vida eterna numa perspectiva interior, que culminou com uma nova descoberta no findar da Antiguidade clássica: a conexão entre a vontade e a liberdade.

Hannah Arendt indica que:

"Santo Agostinho está entre os maiores e mais originais pensadores; não era, porém, um 'pensador sistemático', e é verdade que o corpo principal de sua obra está 'repleto de linhas de pensamento que não vão até as últimas consequências e de empreitada literárias abandonadas - além de estar cheio de repetições"".

Sobre esse assunto, para fundamentar a afirmação de que não era pensador sistemático, mas homem notável que pensava a vida a partir das suas implicações espirituais e não apenas da lembrança ou da misericórdia de Deus, Hannah Arendt afirma que " para Santo Agostinho não se tratava de abandonar as incertezas da filosofia em favor da verdade revelada, mas de descobrir as implicações filosóficas de sua nova fé" ${ }^{10}$.

$\mathrm{Na}$ argumentação de Gerd Bornheim, essas implicações filosóficas agostinianas - de modo específico nos relatos das Confissões - devem ser entendidas como a busca:

“do itinerário de uma alma singular em seus avanços de aproximação da realidade divina. Mais uma vez, o que está em causa concentrase integralmente na pedagogia inerente ao universal concreto" ${ }^{11}$.

Agostinho é o filósofo cristão por excelência e, segundo Hannah

9 ARENDT, Hannah. A vida d Espírito: o pensar, o querer e o julgar. Rio de Janeiro: Relumé Dumará, 1995, p. 249.

$10 \quad$ Idem Ibidem p. 250.

11 BORNHEIM. Gerd. O sujeito e a norma. In: Novaies, Adauto (Org). Ética. São Paulo, 1992, p. 249. 
Arendt, "autoridade no mundo filosófico cristão equivalente à de Aristóteles; para a Idade Média, o filósofo" ${ }^{12}$ que busca, na atividade do pensamento, o universal, isto é, "princípios próprios". ${ }^{13}$

Em resumo: pode-se concluir, nessa primeira parte, que Santo Agostinho, como pensador cristão e romano, foi ao cerne do pensamento metafísico grego e produziu uma interpretação própria da ontologia grega ${ }^{14}$ ao interpretar a situação do homem do seu tempo - que é a linha tênue entre o fim da Idade Antiga e o começo do período medieval - numa perspectiva universalista e toda nova em termos filosóficos e cosmológicos: a faculdade da vontade.

\section{A questão da Vontade}

Hannah Arendt destaca que Santo Agostinho, pensador cristão e romano, "trinta anos mais tarde, de uma forma diferente, em Cidade de Deus, retoma a questão do "propósito do homem"”'15.

A questão do "propósito do homem" é uma análise da filosofia da vontade em Santo Agostinho que teve como ponto de partida uma reflexão

$\overline{12}$ ARENDT, Hannah. A vida d Espírito: o pensar, o querer e o julgar, 1995, p. 250.

13 Segundo Enrico Berti "à teorização da ciência apodíctica é dedicado todo um tratado celebérrimo: os Segundos analíticos. Aristóteles oferece-nos, antes de tudo, uma definição de ciência: 'Pensamos ter ciênciade qualquer coisa em sentido próprio - vale dizer, não de modo sofístico, isto é, por acidente - no caso de pensarmos conhecer a causa pela qual a coisa é (aquilo que é), que ela é causa daquela coisa e que não é possível que esta seja diversamente' (I 2, 71b 9-12). Duas, portanto, são as características da ciência que resultam de tal definição: 1) o conhecimento da causa, que deve ser entendida em sentido lato, isto é como a razão, a explicação de um fato, de um comportamento ou de uma propriedade (para Aristóteles, como é conhecido, há quatro tipo de causas - material, formal, motora e final -, todas suscetíveis de serem objeto da ciência); 2) a necessidade de suas conclusões, isto é, a impossibilidade de que, quando se tem ciência de um certo estado de coisa, as coisas sejam diversamente de como se sabe que são". Ou seja, "A demonstração entendida no sentido mais próprio é aquela que procede de premissas universais para conclusões particulares, isto é, a dedução; ela, portanto, é o que confere à ciência o caráter de conhecimento dotado de necessidade". BERTI, Erico. Aristóteles no século XX, 1998, p. 3-4.6. 
detalhada e original da carta de São Paulo aos Romanos.

São Paulo e Santo Agostinho são dois ícones do pensamento cristão. Foi o apóstolo Paulo o articulador da questão da vontade na interioridade do homem desvinculada das relações políticas e mundanas, mas posta como um vestígio de liberdade dentro do próprio homem.

São Paulo foi o fio condutor de Santo Agostinho na elaboração e na interpretação da filosofia da vontade. São Paulo pertence à tradição judaicocristão e greco-romana; não devemos esquecer que São Paulo era cidadão romano e foi julgado e condenado como tal.

São Paulo era uma autoridade no pensamento cristão e, enquanto autoridade, influenciou profundamente o pensamento de Agostinho e suas análises sobre a questão da vontade.

"Santo Agostinho, porém, não fala de duas leis, mas de duas vontades, de uma nova e outra velha, uma carnal e a outra espiritual, e descreve em detalhe, assim como São Paulo, a maneira como essas vontades lutaram 'dentro' dele e como a discórdia entre elas [lhe] dilacerou a alma"16.

A interferência do pensamento de Paulo na visão de Santo Agostinho produz reflexões paralelas, como das duas leis e das duas vontades, a ponto de ser uma questão crucial nas suas reflexões.

"Em outras palavras, toma cuidado para evitar sua própria heresia maniqueísta inicial, que ensina que dois princípios antagônicos governam o mundo, um bom e um mau, um carnal e um espiritual. Para ele, agora, há somente uma lei, e o primeiro insight, portanto, é o mais óbvio e também o mais surpreendente: 'Non hoc velle quod posse' - querer e poder não são o mesmo"17.

A argumentação de Hannah Arendt ressalta que a vontade e o poder

16 ARENDT, Hannah. A vida d Espírito: o pensar, o querer e o julgar, 1995, p. 251.

$17 \quad$ Idem Ibidem p. 251.

http://www.ucp.br/htmlljoomlaBR/synesis/synesis.htm 
não são iguais, mas reconhece que: "a vontade deve estar presente para que o poder seja produtivo" ${ }^{18}$ Como escreve Hannah Arendt:

"Surpreende ainda que Santo Agostinho concorde com o argumento principal dos estóicos para explicar a predominância da vontade, isto é; 'nada está tanto em nosso poder como a própria vontade, pois não há intervalo; no momento em queremos - lá está"'19.

A vontade e o poder são manifestações que aparecem como fonte das nossas ações, como poder para começar alguma coisa espontaneamente, como um movimento sucessivo que se move a partir do querer, isto é, até que queira ser movido ${ }^{20}$.

Esse movimento é livre e surge da vontade como possibilidade de potencializar as ações humanas entre o querer e o não-querer. Essas se realizam fundamentalmente pela faculdade da vontade e não pelas atividades da razão, do apetite ou desejo.

"Essa prova da liberdade da vontade funda-se exclusivamente em uma força interior da afirmação ou negação que nada tem a ver com qualquer posse ou potestas real - a faculdade necessária para executar os comandos da vontade" ${ }^{21}$.

A liberdade da vontade, fundada na força interior, é uma novidade no mundo Antigo: para os gregos e os romanos, a liberdade não era um problema relacionado com a vontade, mas simplesmente uma relação de ir e vir na polis grega ou na urbes romana.

O problema da liberdade da vontade, inserido por São Paulo e Santo Agostinho como fundamento do pensamento cristão, trouxe novos

$18 \quad$ Cf. Idem Ibidem p. 251.

19 ARENDT, Hannah. A vida d Espírito: o pensar, o querer e o julgar, 1995, p. 251.

20 Cf. Idem Ibidem p. 251.

$21 \quad$ Idem Ibidem p. 251.

http://www.ucp.br/html/joomlaBR/synesis/synesis.htm 
parâmetros para entender o homem no mundo, como um ser carnal e espiritual movido pelo querer e não-poder realizar.

"Sem dúvida o homem carnal, no sentido em que São Paulo o entendia, não pode ser livre; mas o homem espiritual tampouco é livre; o que o intelecto jamais pode provar no espírito é que este não deve simplesmente sujeitar-se a ele, mas deve também querer fazê-lo" ${ }^{\prime 2}$.

A vontade é livre e, para ser livre e começar algo novo, precisa querer. O querer lança o homem no espaço das escolhas e do poder querer ou não querer. Essas decisões, entre o querer e o não-querer, modelam a visão de mundo dos homens por meio das suas ações, quando estes realizam suas escolhas, isto é:

“A faculdade da escolha, tão decisiva para o liberum arbitrium (...) aplica-se aqui (...) exclusivamente à escolha entre nelle e nolle, entre querer e não querer. Este nolle nada tem a ver com o querernão-querer, e não pode ser traduzido como "eu-deixo-de-querer", porque isso sugere ausência de vontade" ${ }^{23}$.

Nas palavras de Étienne Gilson, estamos diante do exercício da liberdade, que é uma das noções mais importantes para o pensamento medieval:

"Uma vontade é livre em vários sentidos diferentes; mas ela o é antes de mais nada pelo fato de que pode querer ou não querer, exercer seu ato ou não exercê-lo, e essa primeira liberdade lhe é essencial. É o que os filósofos cristãos exprimem positivamente, identificando o livre-arbítrio como vontade, ou melhor, como ato de escolher que a vontade exerce; porque quando ela escolhe, ela

\footnotetext{
$22 \quad$ Idem Ibidem p. 251

$23 \quad$ Idem Ibidem p. 252.

http://www.ucp.br/html/joomlaBR/synesis/synesis.htm
} 
quer; é ela que quer, mas também poderia não querer”24.

As palavras de Gilson reforçam as reflexões arendtianas sobre o ato da vontade como um "eu quero" e um "não quero" todo envolvido na trama das escolhas que dilacerou a alma de Santo Agostinho no ato de escolher entre duas vontades. Com isso, surge a questão: "O que é, então, que faz a vontade querer? O que põe a Vontade em movimento? "25.

A vontade, como argumenta Hannah Arendt, é a sua própria causa ou não é vontade; ou seja, a vontade é pura factualidade contingente, que não se explica pela categoria da causalidade. Nesse sentido, Hannah Arendt recorda a "questão da vontade nas Confissões, que são quase totalmente não-argumentativas e ricas no que hoje chamamos descrições 'fenomenológicas' ${ }^{\prime}{ }^{26}$.

As descrições fenomenológicas vivenciadas por Santo Agostinho são comunicações formadas pelas experiências religiosas e filosóficas da finitude humana diante do mundo, do tempo, do amor e de Deus como uma "retirada do mundo, tal como ele nos aparece, e um movimento para trás em direção ao eu" ${ }^{27}$. Um desses, movimentos foi possível quando Santo Agostinho,

"refletindo sobre o que de fato acontecera durante o "combate ardoroso que travara consigo mesmo' antes de sua conversão, (...) descobriu que a interpretação que São Paulo fazia de uma luta entre carne e espírito estava errada. Pois 'meu corpo obedecia mais facilmente à mais fraca das vontades de minha alma, movendo seus membros a um mínimo sinal, do que minha alma obedecia a si mesma para efetuar essa grande vontade que só na vontade pode

\footnotetext{
$24 \quad$ GILSON. Étienne. O espírito da filosofia Medieval, 2006, 372 - 373.

25 ARENDT, Hannah. A vida d Espírito: o pensar, o querer e o julgar, 1995, p. 252.

$26 \quad$ Idem Ibidem p. 254.

$27 \quad$ Idem Ibidem $\mathrm{p} 19$.

http://www.ucp.br/html/joomlaBR/synesis/synesis.htm
} 
ser realizada'28.

A questão da vontade para Santo Agostinho não aparece como São Paulo tinha pensado - numa luta constante entre carne e o espírito -, mas localiza-se na própria faculdade da vontade. Aqui podemos visualizar o distanciamento de Santo Agostinho em relação a São Paulo, que era uma autoridade no pensamento judaico-cristão, ao realizar uma reflexão mais apurada e sofisticada da Vontade. Como afirma Hannah Arendt:

"É da natureza da Vontade duplicar-se, e, neste sentido, onde quer que haja uma vontade, há sempre 'duas vontades, nenhuma das quais é plena (tota), e o que falta a uma está presente na outra'. Por essa razão, são sempre necessárias duas vontades antagônicas para chegar a ter vontade; 'não é, portanto, monstruoso querer em parte e em parte não-querer' ('Et ideo sunt duae voluntates, quia una earum tota non est...Non igitur monstrum partim velle, partim nolle' $)^{29}$.

A vontade se manifesta como um conflito constante: não como um diálogo, que não permite a contradição de pensamento, mas como possibilidade de ruptura, de conflito e contradição, ao querer ou não querer, como num cabo de força ou numa instigante luta entre iguais na realização da vontade ou da contra-vontade dos competidores.

Observa Hannah Arendt que,

"mais tarde em Duns Scotus, a solução do conflito interno da vontade surge por uma transformação na própria vontade, por sua transformação em amor. A vontade - vista em seu aspecto operatório e funcional como um agente de união, de ligação - pode também ser definida como amor (voluntas: amor seu dilectio), pois o amor é obviamente o agente de ligação de maior êxito. No amor,

$28 \quad$ Idem Ibidem $\mathrm{p} 255$.

29 ARENDT, Hannah. A vida d Espírito: o pensar, o querer e o julgar, 1995, p. 255.

http://www.ucp.br/htmlljoomlaBR/synesis/synesis.htm 
há novamente "três coisas: aquele que ama, aquilo que é amado e o Amor... [O Amor] é uma certa vida que liga ... duas coisas, aquele que ama e aquilo que é amado" "’30.

Vale aqui recordar a interpretação da Hannah Arendt sobre o amor como tensão em Santo Agostinho:

"Todo amor é tensão dirigida para essa realização. A realização é a beatitude (beatitudo), que não consiste em amar mas em fruir daquilo que é amado e desejado. Todo amor é tensão dirigida para essa fruição. 'No entanto, ninguém é feliz se não fruir do que ama. Mesmo aqueles que efetivamente amam o que não é preciso amar não acreditam em obter felicidade do seu amor mas da sua fruição'. Fruir é estar perto do objeto desejado, firme e sem inquietude" ${ }^{31}$.

É válido este argumento, na medida em que fundamenta a distinção e as semelhanças entre a vontade e o amor como possibilidade de ligação entre o conflito interno da faculdade da vontade no seu aspecto funcional e operatório.

“... mas vem também do fato de que o amor, ao contrário da vontade e do desejo, não se extingue quando alcança seu objetivo, mas sim possibilita ao espírito 'permanecer imóvel para poder desfrutá10 "' 32

Mas a vontade, ao contrário do amor, nunca se dá por satisfeita, pois está sempre em constante movimento, na dinâmica inquietante entre o querer e o não querer, que só pode aquietar com o desfrute presente do eterno, do amor no tempo.

Para concluir este segundo tópico, podemos argumentar que a faculdade da vontade não é uma faculdade isolada das outras atividades do

\footnotetext{
$30 \quad$ Idem Ibidem p. 261.

31 ARENDT, Hannah. O conceito de amor em Santo Agostinho, 1997, p. 36.

32 ARENDT, Hannah. A vida d Espírito: o pensar, o querer e o julgar, 1995, p. 261.

http://www.ucp.br/html/joomlaBR/synesis/synesis.htm
} 
espírito, mas está em ligação permanente com a memória e o intelecto, como possibilidade interativa das inquietações humanas que se rendem ao desfrute do objeto amado, isto é do amor ${ }^{33}$

\section{A vontade E O PROBLEMA DA LIBERDADE}

O problema da vontade e da liberdade em Santo Agostinho, nas reflexões de Hannah Arendt, configura-se dentro da perspectiva da condição humana, isto é, das questões políticas que se localizam no initium das atividades humanas.

Para fundamentar essa problemática, Hannah Arendt expõe que, no tratado sobre $A$ cidade de Deus, Agostinho retorna ao problema da vontade por meio da perspectiva da temporalidade das faculdades humanas ao intuir Deus como eterno e sem começo: “...fez com que o tempo tivesse um começo; e o homem, que Ele previamente não havia feito, Ele o fez no tempo"34.

Hannah Arendt argumenta que:

"Para que possa haver novidade, ele diz, há de haver um começo: 'e esse começo jamais existira antes', isto é, nunca antes da criação do homem. Portanto, para que um tal começo 'pudesse ser, foi o homem criado sem que ninguém o fosse antes dele' (...). E Santo Agostinho distingue este começo do começo da criação, usando a palavra 'initium' para a criação do homem, mas 'principium' para a criação dos céus e da terra. Quanto às criaturas vivas feitas antes do homem, elas foram criadas 'no plural', como começo de espécies, ao contrário do homem, que foi criado no singular e continuou a 'propagar-se a partir de indivíduos" ${ }^{35}$.

O homem é localizado como a possibilidade de um novo começo

\footnotetext{
33 ARENDT, Hannah. A vida d Espírito: o pensar, o querer e o julgar, 1995, p. 262.

34 Idem Ibidem p. 265.

$35 \quad$ Idem Ibidem p. 266.

http://www.ucp.br/html/joomlaBR/synesis/yynesis.htm
} 
em meio às mudanças e movimento do mundo, distinto dos animais, por criar sentido e dar significado para o próprio initium que surge das suas ações, que foram potencializadas pela capacidade de querer ou não-querer.

O homem aparece como a criatura criada no singular, isto é, como um novo começo que se manifesta na natalidade e se radicaliza na faculdade de agir, como possibilidade de um novo milagre que salva o mundo da sua normalidade e mesmice. ${ }^{36}$

Nas palavras da Hannah Arendt, no monumental livro Origens do totalitarismo, podemos encontrar a seguinte argumentação:

"Beginning, before it before it becomes a historical event, is the supreme capacity of man; politically, it is identical with man's freedom 'Initium ut esset homo creatus est' - 'That a be made man was created' said Augustine. This beginning is guaranteed by each new birth; it is indeed every man" ${ }^{37}$.

A natalidade é um novo início, através de um novo começo manifestado nas ações humanas reveladas pelas atividades que se inserem no mundo, por meio do nascimento. Nas palavras do livro A condição humana:

"It is, in other words, the birth of new men and the new beginning, the action they are capable of by virtue of born. Only the full experience of this capacity can bestow upon human affairs faith and hope, those two essential characteristics of human existence which Greek antiquity ignored altogether, discounting the keeping of faith as a very uncommon and not too important virtue and

\footnotetext{
$36 \quad$ Hannah Arendt, argumenta na obra On Revolution: "What saves the act of beginning from its own arbitrariness is that it carries its own principle within itself, or, to be more precise, that beginning and principle, principium an and principle, are not only related to each other, but are coeval. The absolute from which the beginning is to derive its own validity and which must save it, as it were, from its inherent arbitrariness is the principle which, together with it, makes its appearance in the world. The way the beginner starts whatever he intends to do lays down the law of action for those who have joined him in order to partake in the enterprise and to bring about its accomplishment. As such, the principle inspires the deeds that are to follow and remains apparent as long as the action lasts" ARENDT, Hannah. On Revolution, $213-214$.

ARENDT, Hannah. The Origins of Totalitarianism, p. 479. 
counting hope among the evils of illusion in Pandora's box"38.

Essas questões, postas acima, colocam a liberdade como a possibilidade de um novo começo, e as ações humanas como possibilidades imprevisíveis na realização dos eventos humanos na história, concebendo a existência do homem como autor dos milagres, que salvam o mundo por meio da ação e da liberdade, que rompem com a normalidade e os carregam de fé e esperança para lidar com os negócios humanos na esfera pública.

$\mathrm{Na}$ visão de Hannah Arendt, Santo Agostinho conduziu suas reflexões sobre a liberdade da vontade como liberum arbitrium: a escolha entre $o$ querer $e$ o não-querer que se configura por "uma disposição humana íntima, mas com um caráter da existência humana no mundo ${ }^{39}$ ", na perspectiva da natalidade e não no sentido da condição mortal do homem, como compreendiam os gregos, e muito menos no sentido da liberdade de que fala Kant na Crítica da razão pura:

“..., a alma humana, não se poderia afirmar que a sua vontade era livre e ao mesmo tempo sujeita à necessidade natural, isto é, não livre, sem incorrermos em manifesta contradição, visto que em ambas as proposições tomei alma no mesmo sentido, ou seja, como coisa em geral (como coisa em si) e nem de outro modo podia proceder sem uma crítica prévia. Se, porém, a crítica não errou, ensinando a tomar o objeto em dois sentidos diferentes, isto é, como fenômeno e como coisa em si; se estivesse certa a dedução dos seus conceitos do entendimento e se, por conseguinte, o principio da causalidade se referir tão somente às coisas tomadas no primeiro sentido, isto é, enquanto objeto da experiência e se as mesmas coisas, tomadas no segundo sentido, lhe não estiverem sujeitas, então essa mesma vontade pode, por um lado, na ordem dos fenômenos (das ações visíveis), pensar-se necessariamente sujeita às leis da natureza, ou seja, como não livre; por outro lado,

38 ARENDT, Hannah. The Human Condition, p. 247.

39 ARENDT, Hannah. Entre o Passado e o Futuro, 1992, p. 216.

http://www.ucp.br/htmlljoomlaBR/synesis/synesis.htm 
enquanto pertencente a uma coisa em si, não sujeita a essa lei e, portanto, livre, sem que deste modo haja contradição"

Portanto, Kant deixa explícito que:

"Nunca posso, portanto, nem sequer para o uso prático necessário da minha razão, admitir Deus, liberdade e imortalidade, sem ao mesmo tempo recusar à razão especulativa a sua pretensão injusta a intuições transcendentes; porquanto, para as alcançar, teria necessariamente de se servir de princípios que, reportando-se de fato apenas aos objetos de experiência possível, se fossem aplicados a algo que não pode ser objeto de experiência converteriam realmente em fenômeno, desta sorte impossibilitando toda a extensão prática da razão pura"41.

Kant demonstra que a liberdade se enquadra no âmbito do suprassensível, mas que se manifesta na realidade das ações humanas sem aquela espontaneidade relativamente absoluta que produz embaraço ao entendimento humano da razão pura que, no entender da Hannah Arendt, se fundamenta pela ausência do conhecimento de Kant sobre a filosofia da natalidade de Santo Agostinho: os seres humanos aparecem continuamente num "mundo que os procede no tempo", como recém chegados de fato.

Contudo, Hannah Arendt demarca "a liberdade de espontaneidade" como fundamento da condição humana no tempo, e a vontade como seu órgão do espiritual, isto é, da "Vida do Espírito"42.

Em síntese, o problema da vontade em Santo Agostinho é a experiência do começo e da novidade humana que se instaura no mundo pelo dado factual do princípio da natalidade (paradoxo) no tempo, que conduz o

40 KANT, Immanuel. Critica da Razão Pura, 1994, p. 26.

$41 \quad$ Idem Ibidem p. 27.

42 ARENDT, Hannah. A vida d Espírito: o pensar, o querer e o julgar, 1995, p. 262.

http://www.ucp.br/htmlljoomlaBR/synesis/synesis.htm 
homem para um fim que emerge da sua capacidade de querer ou não-querer, isto é, de ser livre.

\section{CONSIDERaÇões FinaIS}

Santo Agostinho, o primeiro filósofo cristão e romano, como Hannah Arendt escreveu, tinha para si próprio um problema filosófico localizado na atividade espiritual do querer, que é a vontade.

A vontade é uma questão emblemática, porque pertence ao estatuto filosófico e político. A vida humana no mundo é ação, isto, é liberdade que começa a ser delineada por meio das decisões políticas que são cessadas entre um querer e um não-querer, que começa em meio às atividades interiores ou espirituais do querer.

A vontade para Santo Agostinho é analisada a partir do universo judaico-cristão e greco-romano. No pensamento judaico-cristão, Deus cria a natureza e o homem do Nada. O homem, como criatura de Deus criador, é um ser único, que realiza suas atividades por meio de sua singularidade. O homem é singular e o seu estatuto ontológico é a sua natalidade, a possibilidade de um novo começo.

O homem, enquanto um novo começo, é o início de algo novo no mundo, e se realiza por meio de suas ações e decisões, encerradas entre um "não-querer e um querer".

A questão enunciada por Santo Agostinho sobre o problema da vontade, na perspectiva da Hannah Arendt, é política e circunscreve a vida do homem por meio do amor ao mundo. É um desafio fundamental na vida do homem realizar suas atividades no mundo, por meio de ações para preservá-lo e sustentá-lo com cuidado, enquanto espaço de liberdade, de comunicabilidade e de sociabilidade, como pensou Kant.

O mundo criado pelos homens é um espaço de realizações que se revela na pluralidade das práticas humanas e que se configura nas relações 
de coragem, liberdade, amizade e amor ao mundo, tornando possíveis novos inícios criativos por intermédio das suas ações movidas pelo querer, isto é, pela vontade, ao render-se ao objeto amado (desfrute do amado), como problematizou Santo Agostinho na Antiguidade romana, ao pensar a condição da existência humana no mundo.

\section{Bibliografia}

ARENDT, Hannah. The Origins of Totalitarianism. San Diego. A Harvest book, 1976.

. The Human Condition. Chicago: University of Chicago Press, 1998.

. A vida do Espirito: o pensar, o querer e o julgar (tradução de Antonio Abranches, Cesar Augusto R. de Almeida, Helena Martins). Rio de Janeiro: Relumé Dumará, 1995.

. Entre o passado e o futuro (tradução de Mauro W. Barbosa de Almeida). São Paulo: Perspectiva, 1992.

. O conceito de amor em Santo Agostinho (tradução de Alberto Pereira Dinis). Lisboa: Instituto Piaget, 1997. . On Revolution. New York: Penguin Books, 1990.

BORNHEIM, Gerd. O sujeito e a norma. In: NOVAES, Adauto (org.). Ética. São Paulo: Companhia das Letras/Secretaria Municipal de Cultura, 1992.

CÍCERO, Marco Túlio. Sobre a amizade (De Amicitia): edição bilíngue latim-português (tradução de João Teodoro d'Olim Marote). São Paulo: Nova Alexandria, 2006.

GILSON, Étienne. Deus e a filosofia (tradução de Ainda Macedo). Lisboa: Edições 70, 2002.

. O espírito da filosofia medieval (tradução de Eduardo

http://www.ucp.br/html/joomlaBR/synesis/synesis.htm 
Brandão). São Paulo: Martins Fontes, 2006.

KANT, Immanuel. Crítica da razão pura (tradução Manuela Pinto dos Santos e Alexandre Fradique Morujão). Lisboa: Fundação Calouste Gulbenkian, 1994.

LIMA VAZ, Henrique C. de. Antropologia filosófica. São Paulo: Loyola, 2004. (Volume I)

SÊNECA. Sobre a vida feliz (De Vita Beata): edição bilíngue latim-português (tradução de João Teodoro d'Olim Marote). São Paulo: Nova Alexandria, 2005. 